Article

\title{
In Vitro Evaluation of the Effects of Cadmium on Endocytic Uptakes of Proteins into Cultured Proximal Tubule Epithelial Cells
}

\author{
Hitomi Fujishiro, Hazuki Yamamoto, Nobuki Otera, Nanae Oka, Mei Jinno and \\ Seiichiro Himeno *(D) \\ Laboratory of Molecular Nutrition and Toxicology, Faculty of Pharmaceutical Sciences, Tokushima Bunri \\ University, Tokushima 770-8514, Japan; donai-do@ph.bunri-u.ac.jp \\ * Correspondence: himenos@ph.bunri-u.ac.jp; Tel.: +81-88-602-8459
}

Received: 24 February 2020; Accepted: 30 March 2020; Published: 1 April 2020

check for updates

\begin{abstract}
Cadmium (Cd) is an environmental pollutant known to cause dysfunctions of the tubular reabsorption of biomolecules in the kidney. Elevated levels of urinary excretion of low-molecular-weight proteins such as $\beta_{2}$-microglobulin $\left(\beta_{2}-\mathrm{MG}\right)$ have been used as an indicator of $\mathrm{Cd}$-induced renal tubular dysfunctions. However, very few studies have examined the direct effects of $\mathrm{Cd}$ on the reabsorption efficiency of proteins using cultured renal cells. Here, we developed an in vitro assay system for quantifying the endocytic uptakes of fluorescent-labeled proteins by flow cytometry in S1 and S2 cells derived from mouse kidney proximal tubules. Endocytic uptakes of fluorescent-labeled albumin, transferrin, $\beta_{2}-\mathrm{MG}$, and metallothionein into $\mathrm{S} 1$ cells were confirmed by fluorescence imaging and flow cytometry. The exposure of S1 and S2 cells to $\mathrm{Cd}$ at 1 and $3 \mu \mathrm{M}$ for 3 days resulted in significant decreases in the uptakes of $\beta_{2}-\mathrm{MG}$ and metallothionein but not in those of albumin or transferrin. These results suggest that $\mathrm{Cd}$ affects the tubular reabsorption of low-molecular-weight proteins even at nonlethal concentrations. The in vitro assay system developed in this study to evaluate the endocytic uptakes of proteins may serve as a useful tool for detecting toxicants that cause renal tubular dysfunctions.
\end{abstract}

Keywords: kidney; endocytosis; $\beta_{2}$-microglobulin; metallothionein; flow cytometry; proximal tubule epithelial cells

\section{Introduction}

Cadmium $(\mathrm{Cd})$ is an environmental pollutant that causes renal toxicity in animals and humans after chronic exposure in the diet [1]. Due to both the high affinity of $\mathrm{Cd}$ for sulfhydryl moieties in biomolecules within cells and the difficulty of excretion from cells, the biological half-life of $\mathrm{Cd}$ in the human kidney has been calculated to be more than 25 years [2]. The renal accumulation of $\mathrm{Cd}$ results in characteristic renal toxicity is known as Fanconi syndrome at the advanced stage [3-5]. Cd accumulation in the proximal tubules of the kidney has been believed to disturb the reabsorption of the luminal biomolecules, which are filtered through the glomerulus into proximal tubule epithelial cells (PTECs). Animals and humans exposed to $\mathrm{Cd}$ for a long time show increased urinary excretion of glucose, amino acids, and low-molecular-weight (LMW) proteins such as $\beta_{2}$-microglobulin $\left(\beta_{2}-\mathrm{MG}\right)$ and metallothionein (MT) [6-8]. Enhanced urinary levels of $\beta_{2}$-MG have been used as sensitive and reliable indicators of $\mathrm{Cd}$-induced renal tubular damage $[9,10]$.

The reabsorption of luminal biomolecules including $\beta_{2}$-MG and MT by PTECs is mediated by megalin-dependent endocytosis at the apical membrane of PTECs [11-14]. However, many studies on Cd cytotoxicity have focused on the mechanisms of cell lethality, including apoptosis caused by 
Cd [15-17], and only a few studies have examined Cd's direct effects on the efficiency of protein reabsorption by PTECs $[18,19]$, especially under conditions where PTECs are surviving in the presence of Cd.

Recently, we developed an in vitro experimental system using mouse PTEC-derived S1, S2, and $\mathrm{S} 3$ cells, which maintain fundamental features of S1, S2, and S3 segment-specific expression of genes including metal transporters $[20,21]$. In the present study, we attempted to develop an in vitro experimental system for evaluating the endocytosis efficiency of LMW and high-molecular-weight (HMW) proteins into S1 and S2 cells derived from the S1 and S2 segments of proximal tubules where the reabsorption of glomerular-filtered proteins is highly active. To visualize and quantify the amounts of endocytosed proteins, we used fluorescent-labeled albumin, transferrin, $\beta_{2}-\mathrm{MG}$, and MT. Here, we show that flow cytometric analyses of the incorporation of fluorescent-labeled proteins into cultured PTECs can be used to quantitatively evaluate endocytosis efficiency. By using this in vitro assay system, we detected decreases in the endocytic uptakes of $\beta_{2}$-MG and MT in cultured PTECs exposed to Cd.

\section{Materials and Methods}

\subsection{Materials}

Mouse anti-megalin monoclonal antibody was purchased from Abcam (Cambridge, MA, USA). Goat anti-cubilin polyclonal antibody was purchased from Santa Cruz Biotechnology (Dallas, TX, USA). Rabbit anti-transferrin receptor polyclonal antibody was purchased from Abnova (Taipei, Taiwan). Rabbit anti- $\beta$-actin polyclonal antibody, rabbit anti-Early Endosome Antigen 1 (EEA1) antibody, anti-rabbit IgG HRP-linked antibody, anti-mouse IgG HRP-linked antibody, and anti-goat IgG HRP-linked antibody were purchased from Cell Signaling Technology (Danvers, MA, USA). Alexa 555 anti-rabbit IgG antibody was purchased from Invitrogen (Carlsbad, CA, USA). Albumin-fluorescein isothiocyanate conjugate was purchased from Sigma-Aldrich (St. Louis, MO, USA), and Alexa Fluor ${ }^{\circledR}$ 488-conjugated ChromPure Mouse Transferrin was purchased from Jackson ImmunoResearch Laboratories (West Grove, PA, USA). Immortalized human renal proximal tubular epithelial cells (hRPTECs: CRL-4031) was obtained from ATCC (American Type Culture Collection, Manassas, VA, USA).

\subsection{Cell Culture}

S1, S2 cells, and hRPTEC were cultured in Dulbecco's modified Eagle's medium/Ham's Nutrient Mixture F12 supplemented with 5\% fetal bovine serum (FBS), $1 \mu \mathrm{g} / \mathrm{mL}$ insulin, $10 \mathrm{ng} / \mathrm{mL}$ epidermal growth factor, $10 \mu \mathrm{g} / \mathrm{mL}$ transferrin, and penicillin/streptomycin under $5 \% \mathrm{CO}_{2}$ at $37^{\circ} \mathrm{C}$, as described previously [20]. Cells were used at the passages of 3-10 from the stocked original cells.

\subsection{Purification of Recombinant Proteins and Their Fluorescent Labeling}

The cloned mMT-I/pGEX-4T-1 plasmid and mouse $\beta_{2}$-MG/pGEX-4T-1 plasmid were transformed into BL21(DE3)pLysS (Promega, Madison, WI, USA). The selected transformed cells were grown in $10 \mathrm{~mL} \mathrm{SOB}$ medium containing $50 \mu \mathrm{g} / \mathrm{mL}$ ampicillin for $16 \mathrm{~h}$ at $37^{\circ} \mathrm{C}$ until the optical density at $600 \mathrm{~nm}$ reached 0.3-0.4. The expression of MT and $\beta_{2}-\mathrm{MG}$ proteins was induced by incubation with $1 \mathrm{mM}$ IPTG for $6 \mathrm{~h}$ at $37^{\circ} \mathrm{C}$. The cultured cells were harvested by centrifugation at $8000 \mathrm{rpm}$ for $10 \mathrm{~min}$ at $4{ }^{\circ} \mathrm{C}$, and the GST-fusion proteins were purified by using MagneGSTTM Protein Purification (Promega). After a dialysis against PBS, the GST-fusion MT and GST-fusion $\beta_{2}-\mathrm{MG}$ proteins were digested with thrombin (GE Healthcare, Buckinghamshire, UK). The lysates were loaded onto GST GraviTrapTM gravity-flow columns (GE Healthcare) to remove GST proteins, and the lysates were loaded onto a Benzamidine Sepharose 4 Fast Flow resin (GE Healthcare) to remove thrombin.

The purified recombinant MT and $\beta_{2}$-MG proteins were conjugated with fluorescein isothiocyanate (FITC) by Fluorescein Labeling Kit-NH2 (Dojindo, Kumamoto, Japan). For FITC-labeled albumin and 
Alexa-labeled transferrin, commercially available albumin-fluorescein isothiocyanate conjugate and Alexa Fluor ${ }^{\circledR}$ 488-conjugated ChromPure Mouse Transferrin, respectively, were used.

\subsection{Fluorescence Imaging of the Labeled Proteins in S1 Cells}

S1 cells grown in glass-bottom dishes were incubated with each fluorescent-labeled protein and Hoechst33258 for $30 \mathrm{~min}$, washed with phosphate-buffered saline (PBS), fixed with $4 \%$ paraformaldehyde in PBS for $5 \mathrm{~min}$ on ice, and then permeabilized with $0.5 \%$ TritonX-100 in PBS for $15 \mathrm{~min}$ at room temperature.

For the immunostaining of EEA1 to detect the early endosome, the fixed cells were washed with PBS and incubated with a blocking buffer containing bovine serum albumin (BSA) in PBS for $0.5 \mathrm{~h}$ at room temperature. The cells were then incubated with an anti-EEA1 antibody at a 1:100 dilution in blocking buffer for $1 \mathrm{~h}$ at room temperature. After washing with PBS, the cells were incubated with Alexa 555 anti-rabbit IgG at a 1:500 dilution in blocking buffer for $1 \mathrm{~h}$ at room temperature.

The distributions of FITC-albumin and Alexa-transferrin were visualized by a Nikon A1R-Si HD confocal microscope (Nikon, Tokyo, Japan), and those of FITC-MT and $\beta_{2}$-MG were visualized by a BZ-X700 all-in-one fluorescence microscope (Keyence, Osaka, Japan).

\subsection{Assay for Sensitivity to $C d$}

Cells were plated on 96-well plates at a density of $3 \times 10^{3}-2 \times 10^{4}$ cells per well, incubated for $24 \mathrm{~h}$ in $\mathrm{Cd}$-free medium, and then treated with $\mathrm{CdCl}_{2}$ for 1,3 , or 6 days. The media were not changed during the $\mathrm{Cd}$ exposure period. The alamarBlue ${ }^{\circledR}$ assay (Invitrogen) was used to determine cell viability. AlamarBlue solution was premixed with fresh medium and added to the 96-well plates. After incubation for $2 \mathrm{~h}$, the reduction in alamarBlue by active cells was determined by absorbance at $540 \mathrm{~nm}$ and expressed as the percentages compared to that of control cells.

\subsection{Measurement of Endocytosis Efficiency by Flow Cytometry}

Endocytosis efficiency was determined by using flow cytometry (Guava easyCyte 6HT/2L; Millipore, Billerica, MA, USA). S1 and S2 cells $\left(1 \times 10^{5}\right.$ cells in 6-well dishes) were cultured with Cd at the concentrations of 10 or $15 \mu \mathrm{M}$ for 1 day, 1 or $3 \mu \mathrm{M}$ for 3 days, and 0.1 or $0.5 \mu \mathrm{M}$ for 6 days. hRPTECs were cultured with $\mathrm{Cd}$ at the concentrations of 5 or $25 \mathrm{M}$ for 3 days. After the media were changed to $\mathrm{Cd}$ - and serum-free ones, the cells were incubated with each fluorescent-labeled protein for $30 \mathrm{~min}$, washed three times with $0.5 \mathrm{~mL}$ ice-cold PBS, and then harvested and subjected to flow cytometry. In order to quantify the percentages of cell populations incorporating fluorescent proteins, the populations were divided into quadrants, and the percentages of the cell populations in the lower-right section were calculated.

\subsection{Immunoblot Analysis}

Cells were harvested with a lysis buffer, and the extracted proteins were separated by SDS polyacrylamide gel electrophoresis $(7.5-10 \%)$ and electrophoretically transferred to a polyvinylidene fluoride membrane. The transblots were preincubated with $5 \%$ nonfat dry skim milk or BSA in Tris-buffered saline (TBS, $\mathrm{pH} 7.4$ ) and then incubated overnight with the antibody against each protein. After washing with TBS/0.05\% Tween 20, the membranes were incubated with either anti-rabbit, anti-mouse, or anti-goat IgG HRP-linked antibody (1:3000). The membrane was rinsed with TBS/0.05\% Tween 20, and the immunoreactive bands were developed by ECL systems (Millipore Billerica, MA, USA).

\subsection{Statistical Analysis}

Statistically significant differences were determined by one-way ANOVA followed by Bonferroni multiple comparisons using a Statcel 3 software (ver. 3, OMS Publication, Saitama, Japan, 2012). 


\section{Results}

\subsection{Fluorescence Imaging of Endocytic Uptakes of the Labeled Proteins into Mouse PTECs}

We first confirmed the incorporation of fluorescent-labeled proteins into mouse PTECs with confocal and fluorescence microscopes. As shown in Figure 1A, the green fluorescent signals of FITC and Alexa488 were clearly detected in S1 cells $30 \mathrm{~min}$ after the addition of FITC-labeled albumin, $\beta_{2}-\mathrm{MG}, \mathrm{MT}$, and Alexa-labeled transferrin. The yellow fluorescent signals observed in the cells indicate the overlapping of the red fluorescence of the antibody against EEA1 and the green fluorescence of the proteins, suggesting the incorporation of the labeled proteins into the early endosomes.

(A)
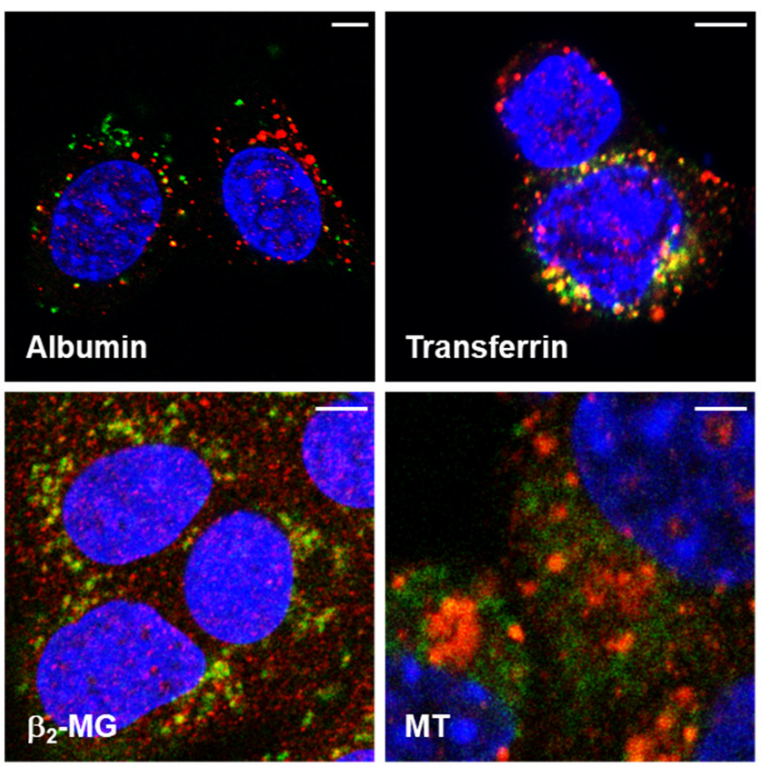

(B)
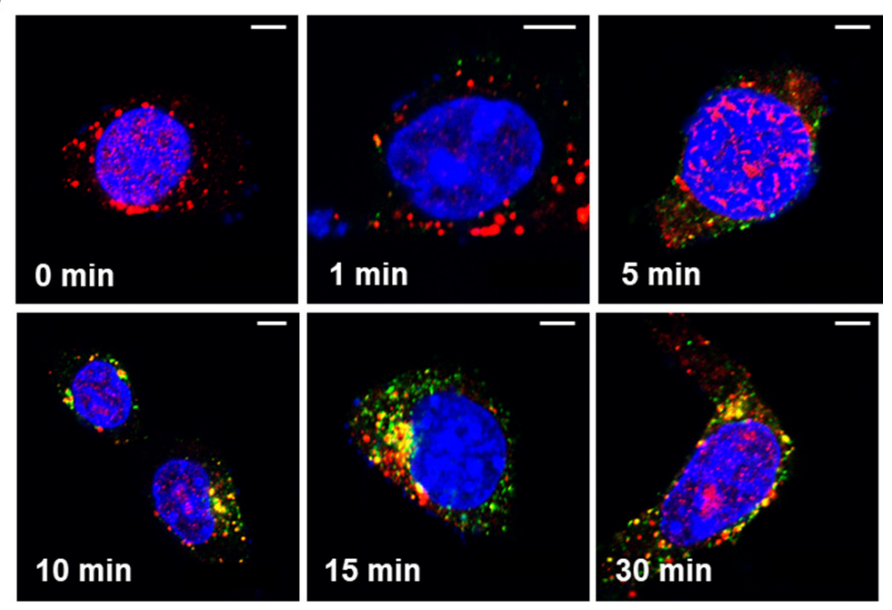

Figure 1. Fluorescence imaging of endocytosed proteins in mouse proximal tubule epithelial cell (PTEC)-derived S1 cells. (A) S1 cells were incubated with $50 \mu \mathrm{g} / \mathrm{mL}$ fluorescein isothiocyanate (FITC)-albumin, Alexa-transferrin, FITC- $\beta_{2}-\mathrm{MG}$, or FITC-MT (green) for $30 \mathrm{~min}$ and then fixed with paraformaldehyde for immunofluorescence labeling with anti-EEA1 (red). Yellow staining demonstrates the colocalization of fluorescent-labeled proteins and early endosomes. (B) S1 cells were incubated with Alexa-transferrin for 1, 5, 10, 15, and $30 \mathrm{~min}$. The localization of Alexa-transferrin (green) and early endosomes stained with anti-EEA1 (red) was visualized by confocal microscopy. Bars, $5 \mu \mathrm{m}$. 
Figure 1B shows the time-dependent changes in the fluorescent signals of transferrin that showed the strongest fluorescent intensities. The green signals of transferrin began to be detected within cells $1 \mathrm{~min}$ after the addition of the protein. Yellow fluorescent signals, indicative of the incorporation of transferrin into the early endosomes, began to appear at $10 \mathrm{~min}$ and then increased up to $30 \mathrm{~min}$. Thus, the results of the fluorescence imaging provided evidence for endocytic incorporation of the labeled proteins into S1 cells.

\subsection{Quantification of Endocytic Uptakes of the Labeled Proteins into Mouse PTECS}

Next, we set up a quantification system for determining the endocytosis efficiency of each protein into the cells by using flow cytometry. The cells were cultured with each fluorescent-labeled protein for $30 \mathrm{~min}$, washed, harvested, and applied to flow cytometry. As shown in Figure 2, the percentages of the cell population in lower-right section in the quadrants were used as the indicator of endocytosis efficiency (\%). Based on the results of preliminary experiments, the amounts of the labeled proteins were decided to be $25 \mu \mathrm{g} / \mathrm{mL}$ for albumin and transferrin and $50 \mu \mathrm{g} / \mathrm{mL}$ for $\beta_{2}-\mathrm{MG}$ and MT as the optimal conditions for incorporation. We used both S1 and S2 cells derived from the S1 and S2 segments of mouse proximal tubules, respectively, since both cell lines showed similar expression levels of megalin, cubilin, and transferrin receptor, which are essential for endocytosis in PTECs (Figure S1). We determined the time-dependent changes in endocytosis efficiency for each protein (Figures S2 and S3). Although these data are obtained by preliminary experiments, it was shown that the uptake rates of albumin and transferrin during 30 min were almost the same between S1 and S2 cells while those of $\beta_{2}-\mathrm{MG}$ and MT were lower into S2 cells than into S1 cells. Since most proteins showed maximal uptakes at $30 \mathrm{~min}$, the effects of $\mathrm{Cd}$ exposure on the endocytic uptakes of these proteins were examined $30 \mathrm{~min}$ after the addition of the labeled proteins in the subsequent experiments.

Albumin

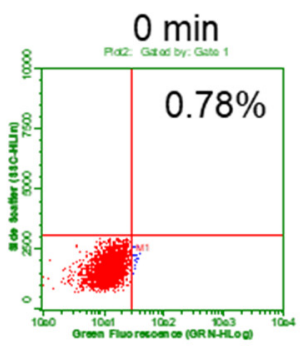

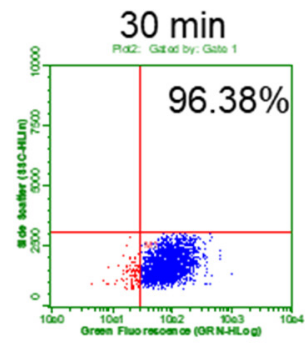

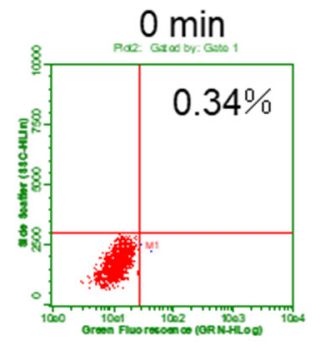

Transferrin

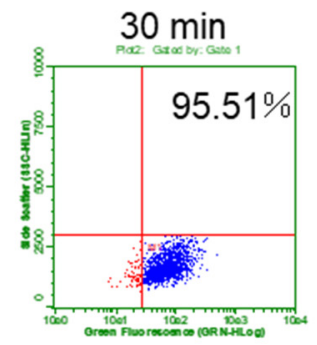

$\beta_{2}-M G$
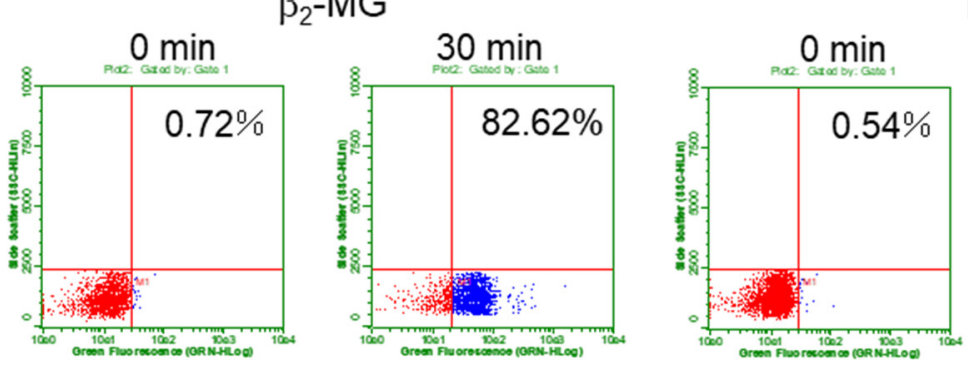

MT

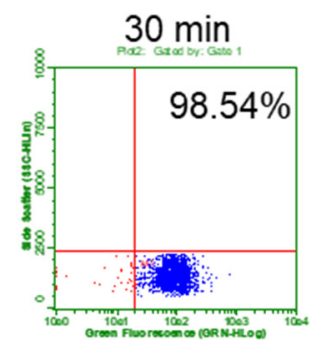

Figure 2. Evaluation of endocytosis efficiency of the fluorescent-labeled proteins by using flow cytometry. The cells were cultured with each of the fluorescent-labeled protein for 0 or $30 \mathrm{~min}$ and applied to flow cytometry. Typical quadrant data of each protein in S1 cells were shown here. X-axis indicates fluorescent intensity and $y$-axis indicates side scattering. The untreated cells ( $0 \mathrm{~min})$ showing the auto-fluorescence were gated to be the lower-left section in the quadrants. The cell populations in the lower-right section were expressed as the percentage of total cells and used as the indicator of endocytosis efficiency (\%) in the subsequent experiments. 
The high efficiency of transferrin incorporation into S1 and S2 cells may be partially caused by the expression of transferrin receptor in these cells (Figure S1). It is known that the transferrin receptor in PTECs is expressed in the basolateral [22] and apical [23] membranes, whereas megalin and cubilin are expressed at the apical membrane [24], suggesting that both uptake systems for transferrin contribute to the highly efficient uptake into the endosomes in S1 cells.

\subsection{Effects of Cd Exposure on the Endocytic Uptakes of the Labeled Proteins into Mouse PTECS}

Before examining the effects of $\mathrm{Cd}$ exposure on the endocytic uptakes of the labeled proteins into S1 and S2 cells, we checked the lethal toxicity of Cd in S1 and S2 cells using the alamarBlue assay (Figure 3). Based on the results of this assay, we selected sublethal doses of $\mathrm{Cd}$, as indicated by the arrows in Figure 3, for the subsequent endocytosis experiments. We also attempted to use much higher doses of $\mathrm{Cd}(5 \mu \mathrm{M} C \mathrm{Cd}$ for 3 days and $1 \mu \mathrm{M} \mathrm{Cd}$ for 6 days), but S1 and S2 cells could not survive these concentrations of $\mathrm{Cd}$ when cultured in 6-well plates for endocytosis experiments. The discrepancy in cytotoxicity between the 96-well (alamarBlue ${ }^{\circledR}$ assay) and 6-well plates may be attributable to the differences in cell density. Therefore, in the endocytosis experiments we used 10 and $15 \mu \mathrm{M} \mathrm{Cd}$ for 1 day, 1 and $3 \mu \mathrm{M} \mathrm{Cd}$ for 3 days, and 0.1 and $0.5 \mu \mathrm{M} \mathrm{Cd}$ for 6 days. Under these conditions, very few cells were found to be detached from the plates at the end of $\mathrm{Cd}$ exposure, and the three-times washing of the cells with ice-cold PBS before harvesting did not result in the detachment of the cells. Thus, the effects of $\mathrm{Cd}$ on the endocytosis efficiencies in the following experiments were carried out with the cells including least populations of dead cells.

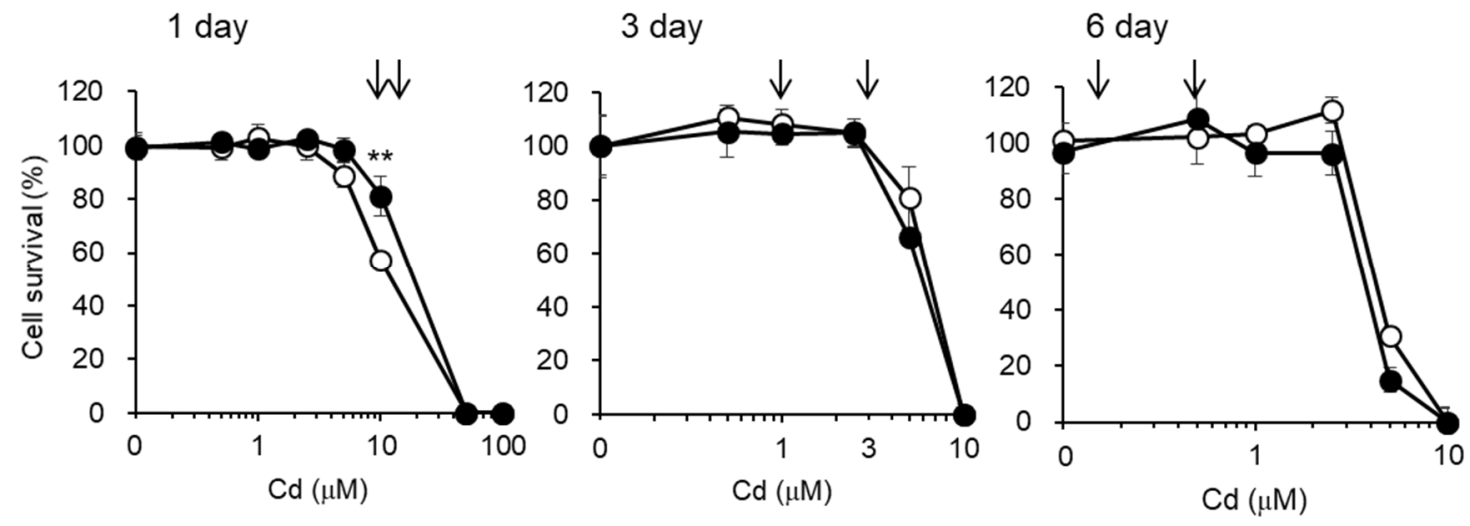

Figure 3. Cytotoxicity of Cd in S1 and S2 cells. S1 (open circles) and S2 (closed circles) cells cultured in 96-well plates were incubated with the indicated concentrations of $\mathrm{CdCl}_{2}$ for 1,3 , and 6 days. Cell viability was determined by alamarBlue ${ }^{\circledR}$ assay and expressed as a percentage of the nontreated cells. From these results, the $\mathrm{Cd}$ concentrations to be used in the subsequent experiments were determined (arrows). Data are presented as means \pm SD $(n=4-6)$. Statistically significant difference between S1 and S2 cells was indicated as ${ }^{* *} p<0.01$.

After the exposure of S1 cells to $\mathrm{Cd}$ at these concentrations for 1, 3, and 6 days, the endocytic uptakes of the labeled albumin and transferrin into S1 cells were examined (Figure 4 and Figure S4). However, Cd exposure did not affect the endocytic uptake of either albumin or transferrin. On the other hand, the endocytic uptakes of $\beta_{2}-\mathrm{MG}$ and MT were affected by $\mathrm{Cd}$ exposure depending on the exposure duration (Figure 5). The 1- and 3-day exposures of S1 and S2 cells to Cd resulted in statistically significant decreases in the endocytic uptake of $\beta_{2}-\mathrm{MG}$ (Figure $5 \mathrm{~A}$ ), whereas only the 3-day exposure to $\mathrm{Cd}$ resulted in statistically significant decreases in endocytic uptakes of MT (Figure 5B and Figure 54 ). The 6-day exposure to $\mathrm{Cd}$ did not cause any significant decreases in endocytic uptakes of either $\beta_{2}$-MG or MT in either cells. 
(A) Albumin
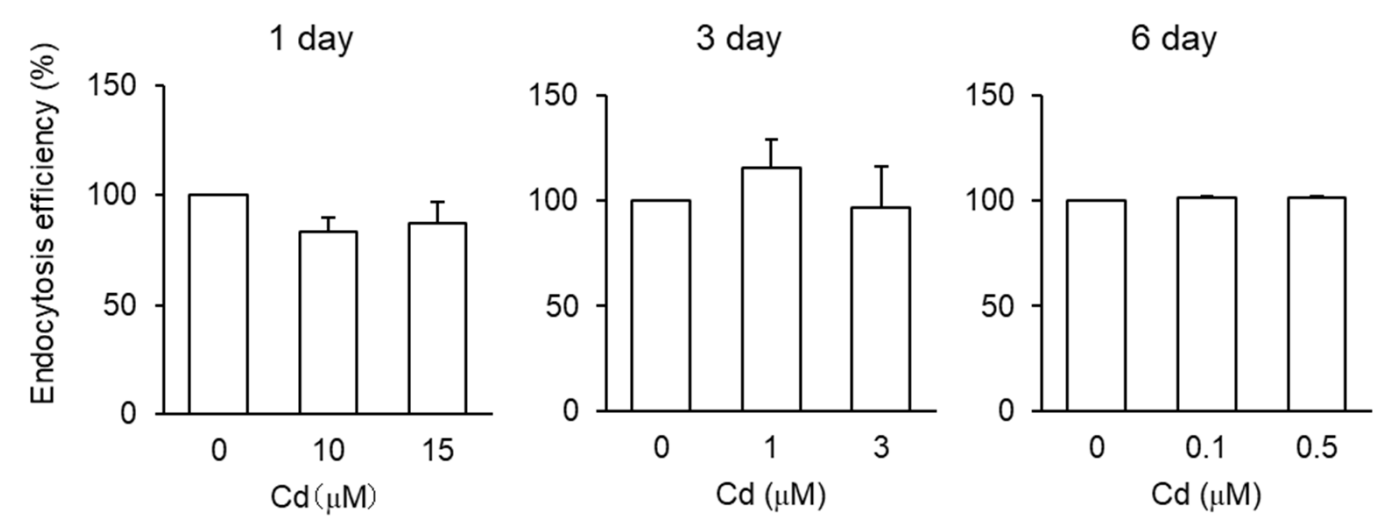

(B) Transferrin
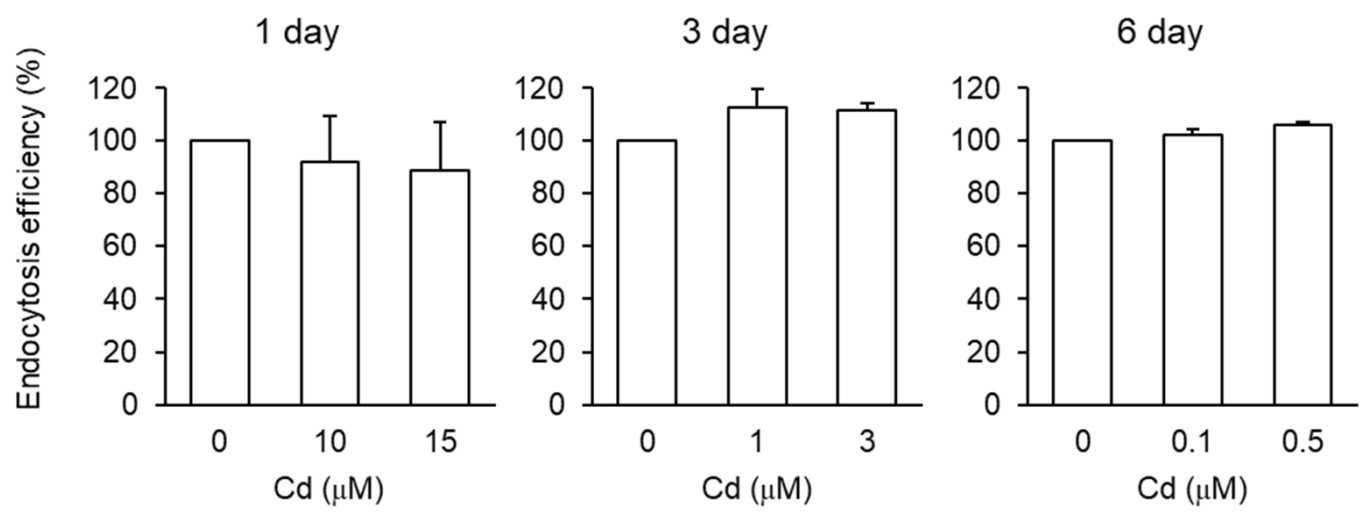

Figure 4. Effects of $\mathrm{Cd}$ on the endocytosis efficiencies of albumin and transferrin into S1 cells. S1 cells were exposed to $\mathrm{CdCl}_{2}$ for 1,3 , and 6 days and then incubated with FITC-albumin (A) or Alexa-transferrin (B) for $30 \mathrm{~min}$. The endocytosis efficiencies were determined by flow cytometry and expressed as percentages of the control cells (no exposure to Cd). Data are presented as means \pm SD $(n=3-4)$.

\subsection{Effects of Cd Exposure on the Endocytic Uptakes of the Labeled Proteins into Human PTECS}

To test whether Cd exposure also affects endocytic uptakes of $\beta_{2}-\mathrm{MG}$ and MT in human PTECs, we utilized hRPTECs, an immortalized cell line derived from human kidney PTECs. Since the effects of $\mathrm{Cd}$ on the endocytic uptakes of $\beta_{2}$-MG and MT in mouse S1 and S2 cells were clearly detected after the 3-day exposure to $\mathrm{Cd}$ (Figure 5), hRPTECs were exposed to $\mathrm{Cd}$ for 3 days. Prior to the endocytosis experiment, we checked the sensitivity of hRPTECs to Cd. As shown in Figure 6A, hRPTECs were highly resistant to $\mathrm{Cd}$ compared with $\mathrm{S} 1$ or $\mathrm{S} 2$ cells. Therefore, we used 5 and $25 \mu \mathrm{M} \mathrm{Cd}$ for endocytosis experiments in hRPTECs. As shown in Figure $6 \mathrm{~B}$, the endocytic uptakes of both $\beta_{2}$-MG and MT were significantly reduced by 3 -day exposure to $\mathrm{Cd}$. 
(A) $\beta_{2}-\mathrm{MG}$
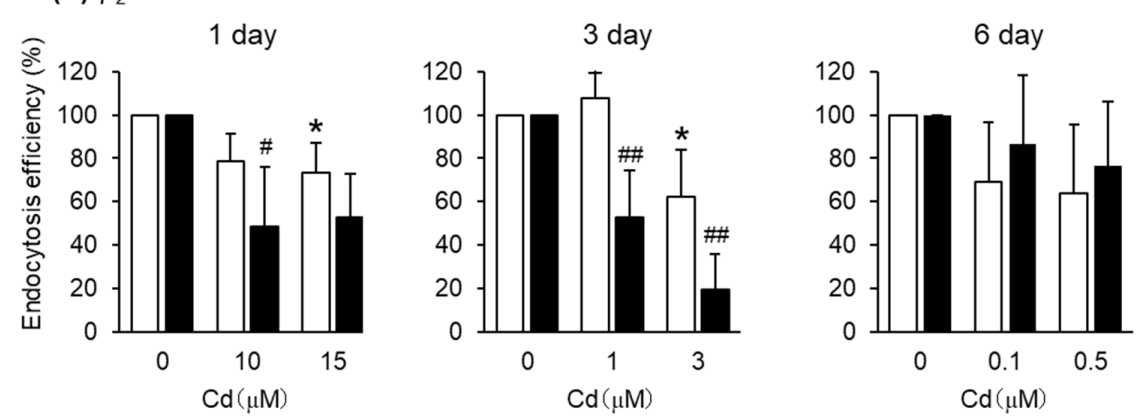

(B) $\mathrm{MT}$
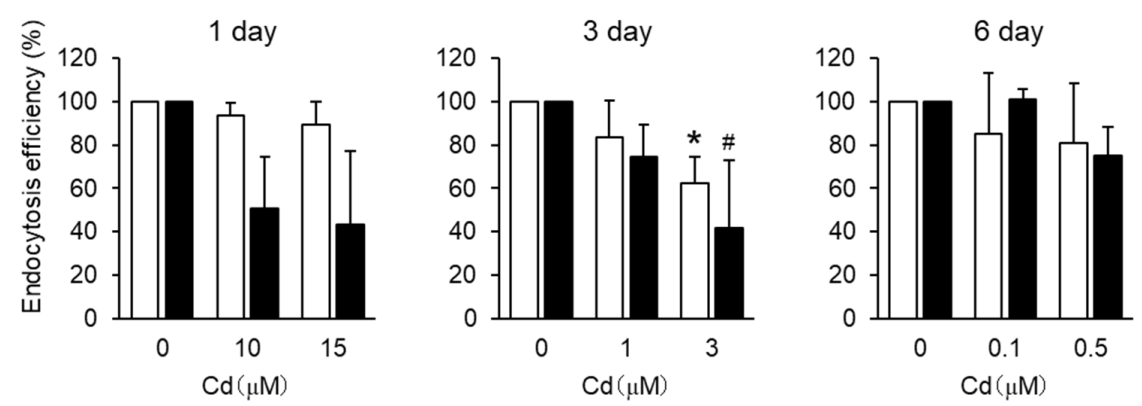

Figure 5. Effects of $C d$ on the endocytosis efficiencies of $\beta_{2}-M G$ and MT into S1 and S2 cells. S1 and S2 cells were exposed to $\mathrm{CdCl}_{2}$ for 1,3 , and 6 days and then incubated with FITC- $\beta_{2}$-MG (A) or FITC-MT (B) for $30 \mathrm{~min}$. The endocytosis efficiencies were determined by flow cytometry and expressed as percentages of the control cells (no exposure to $\mathrm{Cd}$ ). Open and closed columns represent S1 and S2 cells, respectively. Data are presented as means \pm SD $(n=3-4)$. Statistical significance of the dose dependence determined by one-way ANOVA was detected in the following settings: day1-S1 cells $(p<0.05)$, day1-S2 cells $(p<0.05)$, day3-S1 cells $(p<0.05)$, and day3-S2 cells $(p<0.01)$ for $\beta_{2}$-MG (A), and day3-S1 cells $(p<0.05)$ and day3-S2 cells $(p<0.05)$ for MT (B). Statistical significances compared with the control cells determined by Bonferroni multiple comparisons are indicated as ${ }^{*} p<0.05$, ** $p<0.01$ (S1 cells) and \# $p<0.05$, \#\# $p<0.01$ (S2 cells).

(A) Cd cytotoxicity

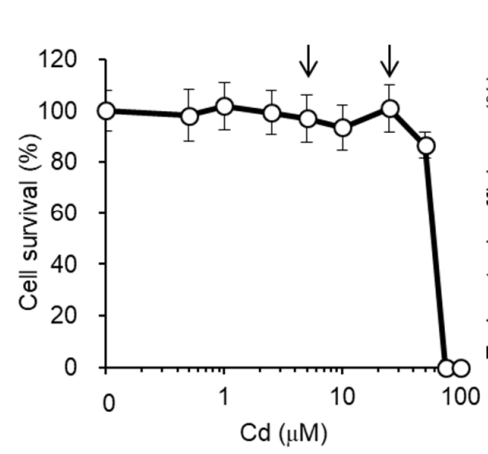

(B) Endocytosis efficiency

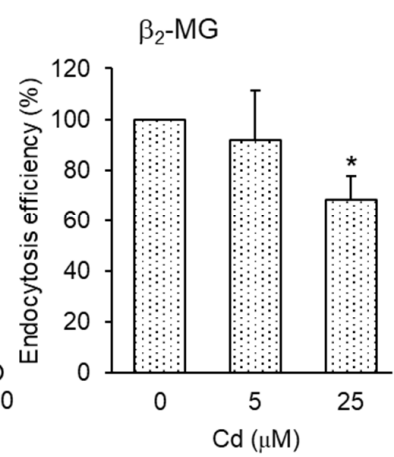

MT

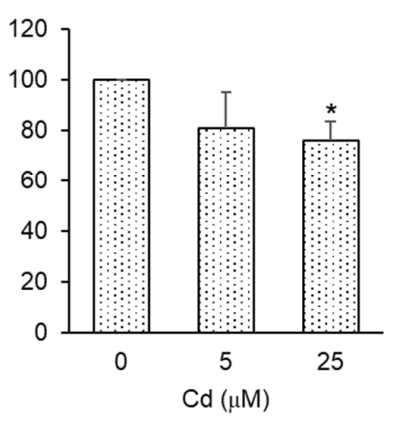

Figure 6. The effects of $C d$ exposure for 3 days on the endocytosis efficiencies of $\beta_{2}-\mathrm{MG}$ and MT into hRPTEC human renal cells. (A) Cell viability was determined by alamarBlue assay and expressed as the percentages of the nontreated cells. From these results, the $\mathrm{Cd}$ concentrations to be used in the endocytosis experiment were determined (arrows). Data are presented as means $\pm \operatorname{SD}(n=4-6)$. (B) The cells were exposed to $\mathrm{CdCl}_{2}$ for 3 days and then incubated with FITC- $\beta_{2}$-MG or FITC-MT for 30 min. The endocytosis efficiencies were determined by flow cytometry and expressed as percentages of the control cells (no exposure to Cd). Data are presented as means $\pm \operatorname{SD}(n=3-4)$. Statistical significance of the dose dependence determined by one-way ANOVA was detected in both $\beta_{2}$-MG $(p<0.05)$ and MT $(p<0.05)$. Statistical significance compared with the control cells determined by Bonferroni multiple comparisons are indicated as * $p<0.05$. 


\section{Discussion}

Disturbances in the tubular reabsorption of glomerular-filtered biomolecules by PTECS in kidney are a hallmark of $\mathrm{Cd}$-induced nephrotoxicity. The urinary excretion of $\beta_{2}$-MG has been particularly widely used as an indicator of renal tubular dysfunction among residents of Cd-polluted areas $[6,9,10]$. However, the precise mechanisms underlying Cd-induced dysfunctions of tubular reabsorption of LMW proteins by PTECs have not been fully investigated. This is partly due to the lack of a proper in vitro experimental system.

In the present study, we developed an in vitro experimental system for evaluating the endocytosis efficiency of fluorescent-labeled proteins into cultured PTECs derived from mouse and human kidney. The endocytic uptakes of the labeled proteins and their cellular localization were confirmed by fluorescence imaging (Figure 1). Flowcytometric analyses of the fluorescent-labeled proteins have enabled us to quantitatively evaluate the uptake rates of labeled proteins into S1 and S2 cells (Figure 2). The exposure of these cells to sublethal doses of $\mathrm{Cd}$ for 3 days resulted in significant decreases in the endocytic uptakes of $\beta_{2}-\mathrm{MG}$ and MT (Figure 5), but not in those of albumin or transferrin (Figure 4). These results demonstrated that the assay system developed in this study permitted the detection of Cd-induced declines in renal reabsorption of LMW proteins in cultured PTECs. The reason for the absence of the effects of $\mathrm{Cd}$ after 6-day exposure remains unknown. Possibly, more complicated factors are involved in the 6-day exposure than the 3-day exposure experiments. Although future studies are required for the mechanisms of Cd-induced decreases in the LMW protein uptakes, this assay system may be useful for screening other renal toxicants that may cause damage in tubular reabsorption.

To date, epidemiological studies in humans and experimental studies in animals have linked increases in urinary excretion of LMW proteins such as $\beta_{2}$-MG with the loss of functional PTECs and nephrons in the kidney at the advanced stage of Cd nephrotoxicity [25,26]. Most mechanistic studies on $\mathrm{Cd}$ cytotoxicity have focused on the molecular pathways leading to $\mathrm{Cd}$-associated cell death and not on the direct effects of Cd on the endocytic uptakes of LMW proteins in living PTECs [15-17]. However, the effects of moderately higher, but not lethal, doses of $\mathrm{Cd}$ on the reabsorption efficiencies of LMW proteins by the surviving PTECs remain unclear. The results of this study demonstrated that a 3-day exposure to $\mathrm{Cd}$ resulted in significant declines in the endocytic uptakes of $\beta_{2}$-MG and MT under the conditions in which nonlethal doses of $\mathrm{Cd}$ were used. This could not be ascribed simply to the increase in dead cells after $\mathrm{Cd}$ exposure, since no effects were observed in the endocytosis efficiencies of albumin or transferrin (Figure 4) and only the surviving cells that were not detached from the plates during $\mathrm{Cd}$ exposure were used for flow cytometry analyses. Although a few studies have investigated the effects of Cd on the interactions of LMW proteins with megalin/cubilin systems in cultured renal cells $[18,19]$, the present study utilized flow cytometry for quantitatively evaluating the endocytosis efficiency of the proteins and showed the effects of $\mathrm{Cd}$ on the uptakes of LMW proteins in cultured PTECs.

Although many epidemiological studies undertaken in Cd-polluted areas have demonstrated that urinary excretion of $\beta_{2}-\mathrm{MG}$ is an excellent biomarker for renal tubular dysfunctions $[6,9,10]$, recent evidence suggested that $\beta_{2}$-MG plays much broader roles as a biomarker not only for tubular dysfunctions, but also for glomerular dysfunctions as well as non-renal diseases [27]. The results of our in vitro study added a piece of evidence that the decreased incorporation of $\beta_{2}$-MG into renal tubular cells is involved in Cd-induced kidney damages. Future studies are required to test whether the decrease in the $\beta_{2}-\mathrm{MG}$ incorporation into renal tubular cells is inducible specifically by $\mathrm{Cd}$, or commonly by other renal toxicants using this assay system.

Compared with the uptakes of $\beta_{2}-\mathrm{MG}$ and MT, those of albumin and transferrin by $\mathrm{S} 1$ cells appear to be far less sensitive to $\mathrm{Cd}$ toxicity (Figure 4). Many human studies have suggested that the urinary excretion of $\beta_{2}-\mathrm{MG}$, a LMW protein, reflects damage in renal tubular reabsorption, whereas the urinary excretion of albumin, an HMW protein, may reflect the dysfunction of glomeruli [28-30], although recent evidence has indicated that tubular reabsorption of albumin should not be ignored [31]. The results of this study also demonstrated that substantial amounts of albumin can be taken up by cultured 
PTECs. Although the differences in the endocytic pathways between HMW albumin and LMW $\beta_{2}$-MG remains unclear, the higher sensitivity of $\beta_{2}$-MG than albumin in this in vitro assay system may reflect the in vivo observation that $\beta_{2}-\mathrm{MG}$ is the most sensitive indicator for renal tubular damage caused by Cd exposure [28,29]. Regarding the comparisons between HMW and LMW proteins, the differences in molecular weights, i.e., albumin and MT, could have affected the endocytosis efficiency because we used $25 \mu \mathrm{g} / \mathrm{mL}$ albumin and $50 \mu \mathrm{g} / \mathrm{mL}$ MT as the optimal conditions, not based on a molar basis, in this assay.

The strengths and limitations of this study should be noted. (1) The use of flow cytometry enabled the quantitative evaluation of the endocytosis efficiencies of fluorescent-labeled proteins, (2) the use of both mouse- and human-derived PTECs enabled the confirmation of reproducibility of Cd effects, and (3) the use of sublethal doses of $C d$ enabled the sensitive detection of the effects of $C d$ on the PTECs that survived the lethal toxicity of $\mathrm{Cd}$. However, the observed effects of $\mathrm{Cd}$ on the endocytosis efficiencies of $\beta_{2}$-MG and MT were not so marked, though statistically significant, and the involvements of $\mathrm{Cd}$ cytotoxicity on the results of flow cytometry may not be completely excluded. Since the in vivo dysfunctions of renal tubular reabsorption generally occur under conditions where a large part of nephrons and PTECs is lost $[25,26]$, the in vitro effects of renal toxicants on the endocytosis efficiency in the living PTECs may reflect only a part of the whole events of renal dysfunction. Nevertheless, this in vitro assay system may provide a useful tool for the future screening of other renal toxicants and for more detailed mechanistic studies.

For future applications of this assay system to the detection of possible renal toxicants damaging tubular reabsorption, the merits and disadvantages of this system should be discussed here. Since mouse S1 and S2 cells and human hRPTECs are all immortalized cell lines, they can provide reproducible and reliable results compared with the primary cultured PTECs prepared freshly from the proximal tubules of kidney. In this study, both mouse and human PTECs showed decreases in endocytic uptakes of $\beta_{2}$-MG and MT after the 3-day exposure to Cd. However, approximately ten times higher concentrations of $\mathrm{Cd}$ were required in hRPTECs than in $\mathrm{S} 1$ and $\mathrm{S} 2$ cells to produce similar detrimental effects (Figure 6) due to the high Cd resistance of hRPTECs, which is the major drawback of using hRPTECs. S2 cells showed a lower efficiency of endocytic uptakes of $\beta_{2}$-MG and MT than S1 cells, whereas the uptake efficiencies of albumin and transferrin were similar to those of S1 cells (Figure 2). Although both S1 and S2 cells showed significant decreases in endocytic uptakes of $\beta_{2}$-MG and MT (Figure 5) when exposed to $\mathrm{Cd}$ for 3 days, $\mathrm{S} 1$ cells may be more preferable for screening renal toxicants that affect the endocytic uptakes of LMW proteins, since the uptake efficiencies of LMW proteins under unexposed conditions are stable and reliable in S1 cells. We are now planning a screening study using S1 cells to test whether other renal toxicants affect the endocytic uptakes of $\beta_{2}$-MG.

\section{Conclusions}

The aim of this study was to establish an in vitro assay system for evaluating the efficiency of endocytic uptakes of LMW and HMW proteins labeled with fluorescent moiety in cultured PTECs. Flowcytometric determinations of the uptakes of the fluorescent-labeled proteins into mouse S1 and S2 cells and human hRPTECs enabled us to find that a 3-day exposure to $\mathrm{Cd}$ resulted decreased endocytic uptakes of $\beta_{2}-\mathrm{MG}$ and MT in all these cells. Thus, these cells, especially S1 cells, proved to be useful for the elucidation of the mechanisms of $\mathrm{Cd}$-induced dysfunctions of renal tubular reabsorption. In future studies, this in vitro system can be used to investigate the effects of $\mathrm{Cd}$ exposure on the expression of megalin and cubilin at the apical membrane, the functions of mitochondria, which provide the energy for endocytosis, and other machineries required for the process of endocytosis. This system may also serve as a tool for studying the mechanisms of other toxicants causing renal tubular dysfunctions.

Supplementary Materials: The following are available online at http://www.mdpi.com/2305-6304/8/2/24/s1, Figure S1: Expression levels of the proteins involved in endocytosis in S1 and S2 cells, Figure S2: Time-dependent changes in endocytic uptakes of albumin, transferrin, $\beta_{2}-\mathrm{MG}$, and MT, Figure S3: Time-dependent changes in 
endocytic uptakes of albumin, transferrin, $\beta_{2}-\mathrm{MG}$, and MT, Figure S4: Effects of Cd on the endocytosis efficiencies of albumin and $\beta_{2}$-MG into S1 cells.

Author Contributions: Conceptualization, H.F. and S.H.; cell biology experiments, H.F., H.Y., N.O. (Nobuki Otera), N.O. (Nanae Oka), and M.J.; fluorescence imaging, H.Y., N.O. (Nobuki Otera), and N.O. (Nanae Oka); synthesis and purification of recombinant proteins, H.F., N.O. (Nanae Oka), and M.J.; development of flow cytometric quantification of endocytosis, H.F. and H.Y.; writing and editing, H.F. and S.H. All authors have read and agreed to the published version of the manuscript.

Funding: This work was partly supported by JSPS KAKENHI Grant Numbers 19H05770 (H.F.) and 19H01081 (S.H. and H.F.), and by the Study of Health Effects of Heavy Metals organized by Ministry of the Environment, Japan (S.H.).

Conflicts of Interest: The authors declare no conflict of interest.

\section{References}

1. Himeno, S.; Aoshima, K. (Eds.) Cadmium Toxicity-New Aspects in Human Disease, Rice Contamination, and Cytotoxicity; Springer Nature Switzerland AG: Basel, Switzerland, 2019; ISBN 978-981-13-3630-0.

2. Elinder, C.G.; Lind, B.; Kjellström, T.; Linnman, L.; Friberg, L. Cadmium in kidney cortex, liver, and pancreas from Swedish autopsies. Estimation of biological half time in kidney cortex, considering calorie intake and smoking habits. Arch. Environ. Health 1976, 31, 292-302. [CrossRef] [PubMed]

3. Blainey, J.D.; Adams, R.G.; Brewer, D.B.; Harvey, T.C. Cadmium-induced osteomalacia. Br. J. Ind. Med. 1980, 37, 278-284. [CrossRef]

4. Takebayashi, S.; Jimi, S.; Segawa, M.; Kiyoshi, Y. Cadmium induces osteomalacia mediated by proximal tubular atrophy and disturbances of phosphate reabsorption. A study of 11 autopsies. Pathol. Res. Pract. 2000, 196, 653-663. [CrossRef]

5. Savolainen, H. Cadmium-associated renal disease. Ren. Fail. 1995, 17, 483-487. [CrossRef] [PubMed]

6. Chan, W.Y.; Rennert, O.M. Cadmium nephropathy. Ann. Clin. Lab. Sci. 1981, 11, 229-238.

7. Tohyama, C.; Shaikh, Z.A.; Ellis, K.J.; Cohn, S.H. Metallothionein excretion in urine upon cadmium exposure: Its relationship with liver and kidney cadmium. Toxicology 1981, 22, 181-191. [CrossRef]

8. Satarug, S. Dietary cadmium intake and its effects on kidneys. Toxics 2018, 6, 15. [CrossRef]

9. Ikeda, M.; Ezaki, T.; Moriguchi, J.; Fukui, Y.; Ukai, H.; Okamoto, S.; Sakurai, H. The threshold cadmium level that causes a substantial increase in $\beta_{2}$-microglobulin in urine of general populations. Tohoku J. Exp. Med. 2005, 205, 247-261. [CrossRef]

10. Shiroishi, K.; Kjellström, T.; Kubota, K.; Evrin, P.E.; Anayama, M.; Vesterberg, O.; Shimada, T.; Piscator, M.; Iwata, T.; Nishino, H. Urine analysis for detection of cadmium-induced renal changes, with special reference to $\beta_{2}$-microglobulin. A cooperative study between Japan and Sweden. Environ. Res. 1977, 13, 407-424. [CrossRef]

11. Klassen, R.B.; Crenshaw, K.; Kozyraki, R.; Verroust, P.J.; Tio, L.; Atrian, S.; Allen, P.L.; Hammond, T.G. Megalin mediates renal uptake of heavy metal metallothionein complexes. Am. J. Physiol. Ren. Physiol. 2004, 287, F393-F403. [CrossRef]

12. Christensen, E.I.; Birn, H. Megalin and cubilin: Synergistic endocytic receptors in renal proximal tubule. Am. J. Physiol. Ren. Physiol. 2001, 280, F562-F573. [CrossRef] [PubMed]

13. Sabolic, I.; Ljubojevic, M.; Herak-Kramberger, C.M.; Brown, D. Cd-MT causes endocytosis of brush-border transporters in rat renal proximal tubules. Am. J. Physiol. Ren. Physiol. 2002, 283, F1389-F1402. [CrossRef] [PubMed]

14. Onodera, A.; Tani, M.; Michigami, T.; Yamagata, M.; Min, K.S.; Tanaka, K.; Nakanishi, T.; Kimura, T.; Itoh, N. Role of megalin and the soluble form of its ligand RAP in Cd-metallothionein endocytosis and Cd-metallothionein-induced nephrotoxicity in vivo. Toxicol. Lett. 2012, 212, 91-96. [CrossRef] [PubMed]

15. Tokumoto, M.; Lee, J.Y.; Satoh, M. Transcription factors and downstream genes in cadmium toxicity. Biol. Pharm. Bull. 2019, 42, 1083-1088. [CrossRef]

16. Fujiwara, Y.; Lee, J.Y.; Tokumoto, M.; Satoh, M. Cadmium renal toxicity via apoptotic pathways. Biol. Pharm. Bull. 2012, 35, 1892-1897. [CrossRef] [PubMed]

17. Lee, J.Y.; Tokumoto, M.; Fujiwara, Y.; Hasegawa, T.; Seko, Y.; Shimada, A.; Satoh, M. Accumulation of p53 via down-regulation of UBE2D family genes is a critical pathway for cadmium-induced renal toxicity. Sci. Rep. 2016, 6, 21968. [CrossRef] 
18. Wolff, N.A.; Abouhamed, M.; Verroust, P.J.; Thévenod, F. Megalin-dependent internalization of cadmium-metallothionein and cytotoxicity in cultured renal proximal tubule cells. J. Pharmacol. Exp. Ther. 2006, 318, 782-791. [CrossRef]

19. Fels, J.; Scharner, B.; Zarbock, R.; Zavala Guevara, I.P.; Lee, W.K.; Barbier, O.C.; Thévenod, F. Cadmium complexed with $\beta 2$-microglubulin, albumin and lipocalin-2 rather than metallothionein cause megalin:cubilin dependent toxicity of the renal proximal tubule. Int. J. Mol. Sci. 2019, 20, 2379. [CrossRef]

20. Fujishiro, H.; Hamao, S.; Isawa, M.; Himeno, S. Segment-specific and direction-dependent transport of cadmium and manganese in immortalized S1, S2, and S3 cells derived from mouse kidney proximal tubules. J. Toxicol. Sci. 2019, 44, 611-619. [CrossRef]

21. Fujishiro, H.; Himeno, S. Gene expression profiles of immortalized S1, S2, and S3 cells derived from each segment of mouse kidney proximal tubules. Fundam. Toxicol. Sci. 2019, 6, 117-123. [CrossRef]

22. Fuller, S.D.; Simons, K. Transferrin receptor polarity and recycling accuracy in "tight" and "leaky" strains of Madin-Darby canine kidney cells. J. Cell Biol. 1986, 103, 1767-1779. [CrossRef] [PubMed]

23. Smith, C.P.; Lee, W.K.; Haley, M.; Poulsen, S.B.; Thévenod, F.; Fenton, R.A. Proximal tubule transferrin uptake is modulated by cellular iron and mediated by apical membrane megalin-cubilin complex and transferrin receptor 1. J. Biol. Chem. 2019, 294, 7025-7036. [CrossRef]

24. Nielsen, R.; Christensen, E.I.; Birn, H. Megalin and cubilin in proximal tubule protein reabsorption: From experimental models to human disease. Kidney Int. 2016, 89, 58-67. [CrossRef] [PubMed]

25. Imura, J.; Tsuneyama, K.; Ueda, Y. Novel Pathological Study of Cadmium Nephropathy of Itai-Itai Disease. In Cadmium Toxicity -New Aspects in Human Disease, Rice Contamination, and Cytotoxicity; Himeno, S., Aoshima, K., Eds.; Springer Nature Switzerland AG: Basel, Switzerland, 2019; pp. 39-50.

26. Satarug, S.; Vesey, D.A.; Nishijo, M.; Ruangyuttikarn, W.; Gobe, G.C. The inverse association of glomerular function and urinary $\beta_{2}-\mathrm{MG}$ excretion and its implications for cadmium health risk assessment. Environ. Res. 2019, 173, 40-47. [CrossRef] [PubMed]

27. Argyropoulos, C.P.; Chen, S.S.; Ng, Y.H.; Roumelioti, M.E.; Shaffi, K.; Singh, P.P.; Tzamaloukas, A.H. Rediscovering beta-2 microglobulin as a biomarker across the spectrum of kidney diseases. Front. Med. 2017, 4, 73. [CrossRef] [PubMed]

28. Jin, T.; Wu, X.; Tang, Y.; Nordberg, M.; Bernard, A.; Ye, T.; Kong, Q.; Lundström, N.G.; Nordberg, G.F. Environmental epidemiological study and estimation of benchmark dose for renal dysfunction in a cadmium-polluted area in China. Biometals 2004, 17, 525-530. [CrossRef]

29. Jin, T.; Kong, Q.; Ye, T.; Wu, X.; Nordberg, G.F. Renal dysfunction of cadmium-exposed workers residing in a cadmium-polluted environment. Biometals 2004, 17, 513-518. [CrossRef]

30. Liang, Y.; Lei, L.; Nilsson, J.; Li, H.; Nordberg, M.; Bernard, A.; Nordberg, G.F.; Bergdahl, I.A.; Jin, T. Renal function after reduction in Cadmium exposure: An 8-year follow-up of residents in Cadmium-polluted areas. Environ. Health Perspect. 2012, 120, 223-228. [CrossRef]

31. Dickson, L.E.; Wagner, M.C.; Sandoval, R.M.; Molitoris, B.A. The proximal tubule and albuminuria: Really! J. Am. Soc. Nephrol. 2014, 25, 443-453. [CrossRef]

(C) 2020 by the authors. Licensee MDPI, Basel, Switzerland. This article is an open access article distributed under the terms and conditions of the Creative Commons Attribution (CC BY) license (http://creativecommons.org/licenses/by/4.0/). 